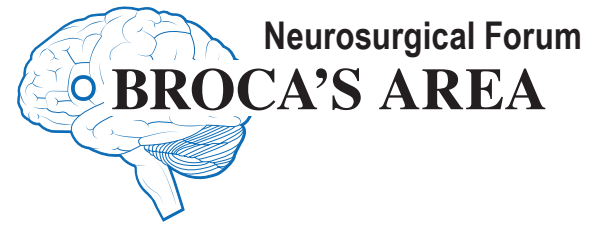

\section{Generating alpha: can we prevent a back pain bubble?}

\author{
John Paul G. Kolcun, MD, ${ }^{1}$ Gregory W. Basil, MD, ${ }^{2}$ \\ Zoher Ghogawala, MD, ${ }^{3}$ and Michael Y. Wang, MD²
}

${ }^{1}$ Department of Neurological Surgery, Rush University Medical Center, Chicago, Illinois; ' ${ }^{2}$ epartment of Neurological Surgery and The Miami Project to Cure Paralysis, University of Miami Miller School of Medicine, Miami, Florida; and ${ }^{3}$ Department of Neurosurgery and The Alan L. \& Jacqueline B. Stuart Spine Research Center, Lahey Hospital and Medical Center, Burlington, Massachusetts

"I T's been a rough time." We sat in shared silence. The young man before me was one of my new patients; I will call him Mr. Lee. He had come to hear those magic words: "Your pain is treatable." Mr. Lee was like many people I had met that day-his back was killing him. He told me about his accident. He told me the pain pulsed and throbbed and shot down his leg. He told me how the leg grew weaker and weaker; how it affected his work. He told me why now more than ever he could not risk his income.

Mr. Lee had purchased a dream house with his wife in 2006. He had had a few good years at work, and a friend had recommended a "great" mortgage broker, who explained to the Lees that although they might be cash-poor now, he could arrange a mortgage package with a lower introductory interest rate; he called it a "teaser" rate. That rate would rise eventually, but so would the value of their property. Housing prices always go up.

Unfortunately for the Lees, it was 2008. They lost the house. Suddenly struggling to stay afloat, Mr. Lee decided to seek extra income by moonlighting in his company's warehouse. He pushed himself too far, and one night in 2010 he felt a sharp "pop" while moving a load of crates. That started him on the well-trodden path of pain pills, chiropractors, and steroid injections that leads so many patients to my clinic.

Now he wanted surgery. He had tried nonoperative measures, which had failed, so he was ready for the "real deal" - a dramatic, abrupt intervention. He wanted his life back. He thought he could be "normal" again. He wanted a moonshot.

I sat down with Mr. Lee to review his MRI and settled in to manage his expectations. Later, after hearing the Lees' experience in the housing market, I had to reflect on his hopes for surgery, what kind of environment we have developed around these procedures, and how sustainable our common practices may be.

If the last decade has taught us anything, it is that we should doubt any system that promises constant, unchecked growth. However, in this same period, the growing trend of quality-based care has begun to dominate the healthcare market, shifting our clinical and financial focus from service-delivered to patient outcomes. ${ }^{1}$ But too often, quality-based systems and their proponents may assume that physicians and hospitals can provide ever-increasing quantities of ever-higher-quality care, with no anticipated ceiling.

Unfortunately, housing prices do not always go up. And value-real clinical and economic value-may not increase indefinitely. We as physicians may be approaching a new runaway system. More patients will find that nonoperative therapy fails them. More will be referred to my clinic. And more will require surgery.

We may be facing a bubble. In economic terms, a "bubble" represents a situation wherein goods or services are traded at higher volumes and for higher prices than are justified by their intrinsic value. ${ }^{2}$ Although the precise conditions for a bubble remain elusive, they are likely to be due to a complex set of circumstances including high credit availability, which reduces purchasing thresholds; information asymmetry, which leads to a poor understanding of true value; and some degree of speculative behavior. ${ }^{3}$

But does this model map to spine surgery? Unfortunately, it may. We anticipate that the aging population will experience greater rates of degenerative disease, thereby increasing demand for treatment. ${ }^{4}$ Shifts in the American 
market, including the Affordable Care Act, have made tertiary care more widely accessible, decreasing the threshold to seek effective operative intervention. ${ }^{5}$ Finally, there is a fundamental asymmetry of information wherein patients may not fully understand the benefits of their surgery. ${ }^{6} \mathrm{We}$ are facing high demand, high access, and nonexpert consumers. These considerations reflect the vital question in understanding our looming bubble: what is the true value of spine surgery?

The clinical answer is obvious: decreased pain and increased functional capacity, all accomplished with minimal risk. But what about the economics? Financially, value can be thought of as relative or absolute. Absolute value represents the intrinsic worth of a good or service. Relative value, however, demands context. What is the opportunity cost of your investment? We automatically reject several options to pursue one course: another steroid injection or a surgical intervention? We also consider time value: one dollar today versus next week may seem equivalent, but the dollar today can be invested to generate greater value next week. Similarly, operating today may achieve more pain-free years, whereas to delay poses opportunity costs and may reduce the likelihood of success.

If we are approaching a healthcare bubble, how can we mitigate its inevitable "burst"? Following the 2008 financial crisis, government bailouts, more stringent lending standards, and improved consumer confidence achieved some relief, but this correction was slow and painful. Perhaps we in the healthcare professions could avoid such a tortuous course: prevention is better than cure.

In facing this problem, we may explore the financial concept of "alpha" - the excess return above a given benchmark.? "Generating alpha" is a mantra among portfolio managers who seek to demonstrate their prowess by outperforming the market for their stakeholders. Alpha is generated with novel investment strategies, advanced riskmanagement analysis, and careful asset selection.

How, then, can we generate alpha in the American landscape of back pain? The first step must be in identifying and prioritizing the stakeholders. It should be self-evident that the most important stakeholders are the patients themselves. However, each patient's disability or lost productivity has tangible downstream socioeconomic implications, making society at large another stakeholder. Hospitals are likewise invested in alpha generation and seem to be in a perpetual cycle of cost cutting and streamlining. Insurance companies, who have a fiducial duty to their investors, are also clearly (and perhaps primarily) concerned with alpha generation-often by limiting utilization of expensive healthcare. Finally, we physicians continually face increasing pressure from hospital administration to generate alpha in practice by augmenting clinical volume. Ultimately, we must maximize alpha for all interested parties.

Let us consider common attempts to generate alpha. More efficient, higher-volume practices are an easy temptation. Many hospital administrators are directing physician leaders to generate greater clinical volume at lower cost. However, this approach hardly impacts the overall value proposition because it is inherently self-limited by the hours in a day, and may actually harm rather than help patients, who may suffer from greater complications and more unnecessary surgeries. Likewise, hospitals seem obsessed with length of stay, pressuring physicians into earlier discharges. Although this approach may be effective for some patients, it may also result in early re-admission, paradoxically increasing cost.

Real solutions need to be developed for complex problems. We acknowledge the need for a multilevel, crossdiscipline approach. Efficiency, cost cutting, value-based care; these magic wands are too often pointed at complex issues with a hand-wave and wishful thinking. We all must work together to generate alpha in the spine: from the first back pain complaint, through imaging and nonoperative management, to the development of clearer guidelines as to when to use interventional procedures and surgery. Success requires the collective efforts and engagement of all parties.

In the financial world, advanced risk analytics proved critical in determining true value in the midst of the economic crisis. Perhaps we as medical professionals would do well to develop similarly advanced analytic tools. This will require all spine professionals to focus on data collection and the development of predictive analytics as well as advanced diagnostic tools. Currently we use registry and other clinical data to calculate risk factors for developing complications or poor outcomes-obesity, diabetes, depression, etc. - and we rightly depend on these data. But now more than ever, we need better diagnostic methodology. We cannot see back pain. We cannot see the suffering that patients like Mr. Lee experience. Therefore, we in the spine community must work to develop that technology, to better optimize both patient selection and surgical outcomes.

Unfortunately, the best strategy today must be to ask the right questions. And to do so, we must first acknowledge this looming economic risk in the field of spine surgery. As I explained to the Lees, there are no moonshots: he eventually underwent a minimally invasive procedure that significantly improved his pain. Further improvement came with Mr. Lee's personal commitment to rehabilitation and physical therapy. Although Mr. Lee's pain never fully resolved, he is now able to work again. Back pain is complex, multifactorial, and managed by well-intentioned professionals doing their best with limited data. To attempt a simple solution is to assume a simple problem, ignoring the hard lessons of the last decade. For Mr. Lee, that means no magic words; for our nation, no magic wands. We must act now as one community: surgeons and clinicians, payers and billers, physicians and patients. We are all shared stakeholders.

\section{References}

1. Jha AK, Joynt KE, Orav EJ, Epstein AM. The long-term effect of premier pay for performance on patient outcomes. $N$ Engl J Med. 2012;366:1606-1615.

2. Girdzijauskas S, Štreimikienè D, Čepinskis J, et al. Formation of economic bubbles: causes and possible preventions. Technol Econ Dev Econ. 2009;15(2):267-180.

3. Abolafia MY. Can speculative bubbles be managed? An institutional approach. Strateg Organ. 2010;8(1):93-100.

4. Colby SL, Ortman JM. Projections of the Size and Composition of the U.S. Population: 2014 to 2060. Washington, DC: US Census Bureau; 2015. https://www.census.gov/content/ 
dam/Census/library/publications/2015/demo/p25-1143.pdf. Accessed January 23, 2020.

5. Miller S, Wherry LR. Health and access to care during the first 2 years of the ACA Medicaid Expansions. $N$ Engl J Med. 2017;376:947-956.

6. Dagi TF. Seven ethical issues affecting neurosurgeons in the context of health care reform. Neurosurgery. 2017;80(4S):S83-S91.

7. Warwick B: Searching for Alpha: The Quest for Exceptional Investment Performance. New York, NY: Wiley; 2000.

\section{Disclosures}

Dr. Wang serves as a consultant to DePuy-Synthes Spine, Stryker,
Spineology, Aesculap Spine, JoiMax, and K2M; receives royalties from Children's Hospital of Los Angeles, DePuy-Synthes Spine, Springer Publishing, and Quality Medical Publishing; holds stock in Innovative Surgical Devices, Medical Device Partners, and Spinicity; and receives grants from the Department of Defense.

\section{Correspondence}

Michael Y. Wang: mwang2@med.miami.edu.

\section{INCLUDE WHEN CITING}

Published online March 6, 2020; DOI: 10.3171/2020.1.SPINE191434.

CAANS 2020, except where prohibited by US copyright law 